Brooks's major scientific work was, appropriate to his training, the study of past climates, on which he was an authority of world renown. His main conclusion in this field, expounded in many papers and in his two books on the subject, "The Evolution of Climate" (1922) and "Climate through the Ages" (1926, second edition 1949), was that the major climatic variations were explicable on the solely geographical grounds of changes in the distribution of land and sea, of relief, and ocean currents. $\mathrm{He}$ recognized the importance of the astronomical factor of changes in the intensity of insolation due to variations in the Sun's radiation and in the Earth's orbit, but considered this as responsible for only the relatively short-period and minor climatic fluctuations. The great ice ages he considered to be disturbances in the generally mild climate of the Earth's history which were associated with the periods of great mountain-building (Caledonian, Alpine, etc.). These conclusions were reached from a profound statistical study of the relation of climate to the distribution of land and sea and ice-cover.

This statistical work made him the leading British expert in statistical meteorology, a subject in which his deep knowledge and skill are shown by his last book, the "Handbook of Statistical Methods in Meteorology", written with Miss Nellie Carruthers (Mrs. A. H. R. Goldie) and published for the Meteorological Office by H.M. Stationery Office in 1953. $\mathrm{He}$ did much, also, on the subjects of seasonal forecasting and solar-terrestrial relations, and, more recently, on the distribution of upper winds ; and he showed great ingenuity in the solution of the problems which come to the Meteorological Office on the application of meteorology to economic and industrial affairs. In the last-mentioned field his book, "Climate in Everyday Life" (1950), is a valuable account of the use of meteorology in many spheres from agriculture to the design of buildings and packing-cases. For twenty-two years he was editor of the Meteor. ological Magazine.

He was for long the world's leading meteorological bibliographer. He made the Meteorological Office Library, of which he was for many years in charge, a great storehouse of knowledge, comprehensively and exactly recorded, and completely recast the meteorological section of the Universal Decimal Classification to fit it for the accurate recording of the great new increases in knowledge of the past forty years. $\mathrm{He}$ represented the Office on the Climatological and Bibliographical Commissions of the International Meteorological Organization and attended several meetings of those bodies.

Brooks served the Royal Meteorological Society, of which he was Buchan prizeman in 1931, as honorary secretary, librarian, vice-president and councillor, holding one or more of these offices almost continuously from 1916 until 1948. The Society's Quarterly Journal published more than sixty original papers of which he was sole or part author. After retiring, he collaborated in the production of the American Meteorological Society's Meteorological Abstracts and Bibliography, and contributed to it some ten thousand abstracts of British and German articles.

Brooks was a man of great energy and enthusiasm which were by no means used solely in scientific work. He played at first board for the Air Ministry Chess Club for many years and was an enthusiast for bridge, lawn tennis and swimnaing. Memorable, too, is his care for the welfare of his staff, notably in the difficult dispersal of war-time.

$\mathrm{He}$ married in 1916 Miss Dora Buckeridge, then a colleague in the Office, and she survives him with their son.

G. A. BuLL

\section{Dr. T. A. Henry}

Thomas Anderson Henry died in Fulham Hospital, London, on May 4 at the age of eighty-five, after a fall at his home. He was born in Dundee on January 20, 1873, but received his early education in Barrow-in-Furness. Like many of his generation, he started his chemical career through pharmacy. After serving his apprenticeship, he moved to London in 1893, when he was awarded the senior Jacob Bell scholarship and passed the Minor and Major Examinations of the Pharmaceutical Society in 1895. The following two years he spent in the Society's research laboratories while holding the Redwood and Manchester scholarships.

In 1896 Dr. Henry was appointed to the scientific research staff of the Imperial Institute, and ultimately became superintendent of laboratories. During this fruitful period at the Imperial Institute he held a Salters Research Fellowship and was awarded the D.Sc. degree of the University of London. During this time, also, he became interested in, and examined, a large number of natural products of economic and scientific importance, among which were cyanogenetic glycosides and alkaloids. With the late Sir Wyndham Dunstan he published more than a dozen papers on cyanogenetic glycosides. He also began writing the book by which he will long be remembered, "The Plant Alkaloids". First published in 1913, the book was until quite recently unrivalled and reached the fourth edition in 1949. Even to-day, nine years after publication, this edition is still widely used and quoted.

In 1919 Dr. Henry left the Imperial Institute to succeed the late Prof. F. L. Pyman as director of the Wellcome Chemical Research Laboratories, a post which he retained until his retirement in 1943. While maintaining his interest in alkaloids, on which he published many papers and inspired others, he developed an interest in chemotherapy, particularly in relation to tropical diseases.

In the laboratory, Dr. Henry was a strict disciplinarian; a meticulous worker himself, he expected a similar high standard from his staff. He could be especially severe with slipshod writing, for he himself was a master of the exact word and apt phrase. But 'off parade' there emerged a charming, modest and kindly man with the interests and welfare of his staff much at heart; many of his technicians owe to him their first chance of advancement. Dr. Henry was of considerable literary erudition, had wide cultural interests and was fond of drama and the theatre. He was much interested in paintings and spent many holidays in Europe visiting art galleries.

In 1927 Dr. Henry was awarded the Hanbury Memorial Medal "for high excellence in the prosecution of research". He was a vice-president of the Chemical Society, served on its Council and Publications Committee and was chairman of the Library Committee. He also served on committees of the British Pharmacopcia Commission and the British Pharmaceutical Codex. He was an original member of the Biochemical Society.
T. M. SHARP 